Original Article

\title{
Periodontal regeneration with autologous periodontal ligament- derived cell sheets - A safety and efficacy study in ten patients
}

\author{
Takanori Iwata a, b, *, Masayuki Yamato a, Kaoru Washio a , Toshiyuki Yoshida a \\ Yuka Tsumanuma ${ }^{c}$, Azusa Yamada ${ }^{c}$, Satoru Onizuka ${ }^{\mathrm{a}, \mathrm{b}, \mathrm{c}}$, Yuichi Izumi ${ }^{\mathrm{c}}$, \\ Tomohiro Ando $^{\mathrm{b}}$, Teruo Okano ${ }^{\mathrm{a}, * *}$, Isao Ishikawa ${ }^{\mathrm{a}}$ \\ a Institute of Advanced Biomedical Engineering and Science, Tokyo Women's Medical University, 8-1 Kawada-cho, Shinjuku-ku, Tokyo 162-8666, Japan \\ ${ }^{\mathrm{b}}$ Department of Oral and Maxillofacial Surgery, Tokyo Women's Medical University, 8-1 Kawada-cho, Shinjuku-ku, Tokyo 162-8666, Japan

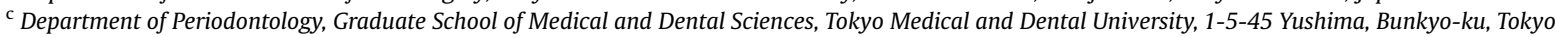 \\ 113-8510, Japan
}

\section{A R T I C L E I N F O}

\section{Article history:}

Received 22 June 2018

Received in revised form

29 June 2018

Accepted 3 July 2018

\section{Keywords:}

Periodontal regeneration

Cytotherapy

Cell sheet

Clinical study

Multipotent mesenchymal stromal cells (MSCs)

Periodontal ligament

Cone-beam computed tomography (CBCT)

Stem cells

\begin{abstract}
A B S T R A C T
Background: Periodontitis results in the destruction of tooth-supporting periodontal tissues and does not have the ability to heal spontaneously. Various approaches have been introduced to regenerate periodontal tissues; however, these approaches have limited efficacy for treating severe defects. Cytotherapies combine stem cell biology and tissue engineering to form a promising approach for overcoming these limitations. In this study, we isolated periodontal ligament (PDL)-derived cells from patients and created cell sheets with "Cell Sheet Engineering Technology", using temperature responsive culture dishes, in which all the cultured cells can be harvested as an intact transplantable cell sheet by reducing the temperature of the culture dish. Subsequently, the safety and efficacy of autologous PDLderived cell sheets were evaluated in a clinical setting.

Methods: A single-arm and single-institute clinical study was performed to verify the safety and efficacy of autologous PDL-derived cell sheets in patients with periodontitis. Wisdom teeth were extracted from patients diagnosed with chronic periodontitis, ranging in age from 33 to 63 years (mean $[ \pm S D], 46 \pm 12$ ), and periodontal tissues were scraped for cell sources. Three-layered PDL-derived cell sheets were constructed using temperature-responsive culture dishes and transplanted in an autologous fashion following standard flap surgeries. Bony defects were filled with beta-tricalcium phosphate granules. Clinical variables were evaluated at baseline, 3 months, and 6 months. Cone-beam computed tomography was performed at baseline and 6 months. Additionally, mid-long-term follow-up has been performed with patients' agreements.

Results: Our method was found to be safe and no severe adverse events were identified. All the findings, including reduction of periodontal probing depth (mean \pm SD, $3.2 \pm 1.9 \mathrm{~mm}$ ), clinical attachment gain $(2.5 \pm 2.6 \mathrm{~mm})$, and increase of radiographic bone height $(2.3 \pm 1.8 \mathrm{~mm})$, were improved in all 10 cases at 6 months after the transplantation. These therapeutic effects were sustained during a mean follow-up period of $55 \pm 19$ months, and there were no serious adverse events.

Conclusions: The results of this study validate the safety and efficacy of autologous PDL-derived cell sheets in severe periodontal defects, and the stability of this efficacy during mid-long-term follow up. This cytotherapeutic approach, based on cell sheet engineering, offers an innovative strategy to treat the recognized unmet need of treating severe periodontal defects.
\end{abstract}

() 2018, The Japanese Society for Regenerative Medicine. Production and hosting by Elsevier B.V. This is an open access article under the CC BY-NC-ND license (http://creativecommons.org/licenses/by-nc-nd/

$4.0 /)$.

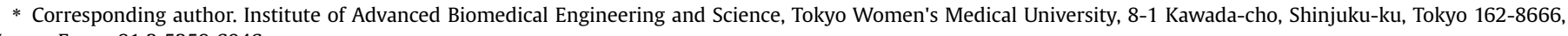
Japan. Fax: +81353596046.

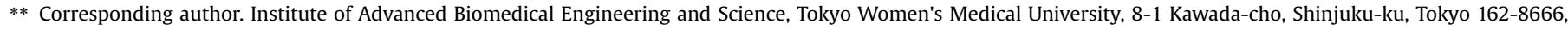
Japan. Fax: +8135359 6046 .

E-mail addresses: iwata.takanori@twmu.ac.jp (T. Iwata), okano.teruo@twmu.ac.jp (T. Okano).

Peer review under responsibility of the Japanese Society for Regenerative Medicine.
} 


\section{Introduction}

Periodontitis (gum disease) is a bacteria-induced inflammatory disease that affects the supporting structures of the teeth, including the jawbone, periodontal ligament (PDL), and cementum. Periodontitis not only gives rise to functional and esthetic problems in the oral cavity, but is also associated with systemic diseases, such as diabetes, preterm birth, cardiovascular disease, stroke, and pulmonary disease [1]. Conventional treatments can only delay the progress of the condition, and the therapeutic effect of various resection surgeries is considered minimal. To mitigate these limitations, regenerative therapies have been investigated for almost 100 years [2]. Bone grafts, barrier membranes, and other biological materials have been approved in clinics for the treatment of relatively small size defects; however, there are no appropriate therapies for severe defects, such as one-wall intrabony defects, class III furcation defects, and horizontal defects. The majority of periodontal defects are of these severe defect shapes [3], therefore cytotherapeutic approaches have been investigated during the $21 \mathrm{st}$ century based on the development of tissue engineering and stem cell biology [4].

Stem cells were identified from human PDL tissue and suggested as a promising cell source for periodontal regeneration $[5,6]$. At the same time, our laboratory developed "Cell Sheet Engineering Technology", using a temperature responsive cell culture surface [7], in which all the cultured cells can be harvested as an intact transplantable cell sheet by reducing the temperature of the culture dish. Several clinical studies using "Cell Sheet Engineering Technology" have been reported, such as corneal reconstruction [8], treating cardiomyopathy [9], endoscopic treatment of esophageal ulceration [10], and middle ear mucosal regeneration [11], and the safety and efficacy of these autologous cell sheet therapies were observed. Our group focused on PDL-derived cells and combined them with this technology to create PDL-derived cell sheets. Previous animal experiments showed the efficacy of PDL-derived cell sheets in several experimental periodontal defect models [12-15]. Additionally, we established the optimal extraction and cultivation methods for human PDL-derived cells [6], and the safety of these cells was confirmed $[16,17]$.

In this study, we examined the safety of autologous PDL-derived cell sheets combined with beta-tricalcium phosphate, and the regenerative potential of this new approach in a clinical setting.

\section{Experimental methods}

This study was conducted according to the principles expressed in the Declaration of Helsinki and approved by both the Institutional Review Board of Tokyo Women's Medical University (TWMU) Human Subjects Research and the Japanese Minister of Health, Labour and Welfare in accordance with the "Guidelines on clinical research using human stem cells". All samples were processed and cultured in the cell processing center of TWMU in accordance with the good manufacture practice (GMP) guidelines. This clinical study was registered with the UMIN Clinical Trials Registry, number UMIN000005027 and monitored by a contract research organization. The overall design of this clinical study to regenerate periodontal tissue is presented in Fig. 1.

\subsection{Patients}

Ten patients, ranging in age from 33 to 63 years (mean $[ \pm S D]$ $46 \pm 12$ ), received autologous PDL-derived cell sheet transplantations from November 2011 to May 2014 (Table 1). All patients gave oral and written informed consent at each invasive event, for a total of 4 times. Patients who had periodontitis with probing

depths of more than $4 \mathrm{~mm}$ after the initial therapy were eligible for inclusion. Other inclusion criteria included age $>20$ years old and existence of a redundant tooth which retained healthy periodontal tissue for a cell source. Exclusion criteria included relevant medical conditions contraindicating surgical interventions (e.g., diabetes mellitus, cardiovascular, kidney, liver, or lung diseases, or compromised immune system), pregnancy or lactation, severe tobacco smoking (more than 11 cigarettes a day), or positive results for hepatitis B, hepatitis C, HIV, HTLV, or syphilis in the initial blood examination. The schedule before transplantation is written in Supplemental Fig. 1.

\subsection{Preparation of autologous sera}

Peripheral blood of each patient was tested to confirm negative results for hepatitis B, hepatitis C, HIV, HTLV, and syphilis. For obtaining autologous serum, $100-125 \mathrm{~mL}$ of peripheral blood was collected before the tooth extraction and transported to the cell processing center (CPC) of Tokyo Women's Medical University. Blood was then transferred to $50 \mathrm{~mL}$ centrifuge tubes and incubated at $37{ }^{\circ} \mathrm{C}$ for $1 \mathrm{~h}$. Centrifugation was performed, and the supernatant was collected. The supernatant was again centrifuged, and the supernatant was filtered and then used as autologous serum in cell cultures.

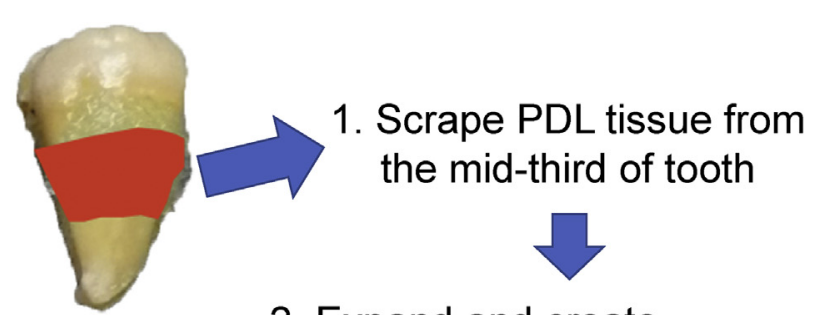

2. Expand and create triple-layered PDL cell sheets

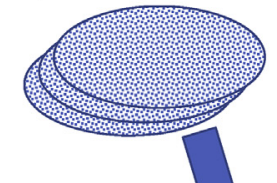

\section{4. $\beta$-tricalcium phosphate granules were filled in bony defects}

\section{Transplant} on the root

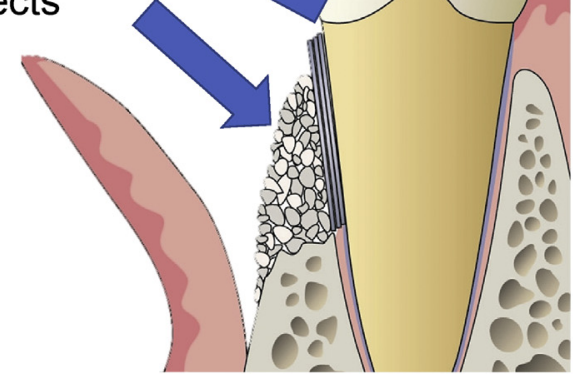

Fig. 1. The procedure of Periodontal regeneration with autologous PDL-derived cell sheets combined with $\beta$-tricalcium phosphate granules. 1. Patients' own redundant tooth was extracted, and PDL tissue was scraped and enzymatically digested to single cells. 2. After expansion, PDL-derived cells were spread on temperature-responsive culture dishes, then triple layered PDL-derived cell sheets were created. 3. Triple layered PDL-derived cell sheets with PGA mesh were trimmed to the defect size and transplanted on the root surface. 4 . $\beta$-tricalcium phosphate granules were filled into bony defects. 
Table 1

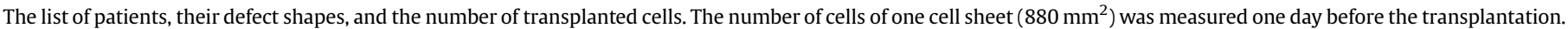

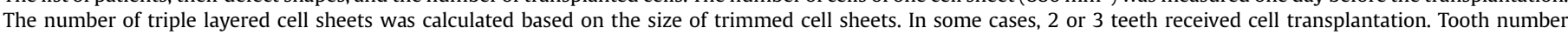
indicates the tooth with the deepest defect.

\begin{tabular}{|c|c|c|c|c|c|c|c|}
\hline No. & y.o./gender & Smoking & Defect shape & Tooth number & Defect position & Million cells/sheet & Estimated transplanted cells (Million) \\
\hline 1 & $33 / \mathrm{M}$ & - & 1 & 47 & Distal-Lingual & 2.00 & 0.64 \\
\hline 2 & $39 / F$ & + & horizontal & 33 & Mesial-Lingual & 1.20 & 0.19 \\
\hline 3 & $52 / \mathrm{F}$ & - & horizontal & $42(43)$ & Distal-Buccal & 0.82 & 0.31 \\
\hline 4 & $63 / F$ & - & horizontal & $47(45,46)$ & Distal-Buccal & 1.20 & 1.23 \\
\hline 5 & $35 / \mathrm{M}$ & former & 1 & 46 & Mesial-Buccal & 0.66 & 0.17 \\
\hline 6 & $58 / F$ & former & circumferential & 17 & Mesial-Buccal & 0.55 & 0.12 \\
\hline 7 & $57 / F$ & former & horizontal & $25(26)$ & Center-Buccal & 0.63 & 0.38 \\
\hline 8 & $36 / \mathrm{M}$ & former & 3 & 36 & Mesial-Lingual & 1.10 & 0.12 \\
\hline 9 & $35 / \mathrm{M}$ & - & 1 & 37 & Distal-Buccal & 1.60 & 0.24 \\
\hline 10 & $54 / \mathrm{M}$ & former & 2 & 44 & Mesial Buccal & 1.30 & 0.53 \\
\hline
\end{tabular}

\subsection{Cell processing and cell sheets}

The PDL-derived cell sheets were created in the cell processing center as previously described [16]. Briefly, PDL tissue obtained from patient's wisdom tooth was digested with collagenase/dispase, and single cell suspensions were passed through a $70-\mu \mathrm{m}$ cell strainer (Falcon, Franklin Lakes, N.J., USA) and incubated on a culture plate (Falcon T-25 flask, primaria; BD Biosciences) in complete medium ( $\alpha$-MEM containing 10\% autologous human serum, 2 mML-glutamine (Sigma-Aldrich), $82.1 \mu \mathrm{g} / \mathrm{mlL}$-ascorbic acid phosphate magnesium salt n-hydrate (Wako Junyaku, Tokyo), $40 \mu \mathrm{g} / \mathrm{ml}$ gentamicin (GENTCIN; Schering-Plough, Osaka), and $0.25 \mu \mathrm{g} / \mathrm{m}$ amphotericin B (FUNGIZONE; Bristol-Myers Squibb, Tokyo)). After 3 passages of expansion in T-75 flasks, cells were seeded on temperature-responsive culture dishes (35 mm in diameter, UpCell ${ }^{\circledR}$, Cell Seed, Tokyo, Japan) at a cell density of $2-4 \times 10^{4}$ cells/dish and cultured in complete medium with additional $82.1 \mu \mathrm{g} / \mathrm{mL}$ L-ascorbic acid phosphate magnesium salt n-hydrate, $10 \mathrm{nM}$ dexamethasone (DEXART; Fuji pharma, Toyama), and $10 \mathrm{mM} \beta$-glycerophosphate (Sigma-Aldrich). Two weeks after culturing in this osteoinductive medium, autologous PDL-derived cell sheets were harvested by reducing the temperature of the culture dish. Prior to the transplantation, the safety and quality control tests for processed cells were performed in vitro as previously described [6,18] (Supplemental Tables 1 and 3 ).

\subsection{Cell sheet transplantation}

The surgical procedure consisted of pre-surgical cleaning, administration of local anesthesia, and reflection of full thickness buccal and lingual flaps to ensure the surgical view. Decontaminating procedures were performed with hand, ultrasonic, and rotary instruments, and the exposed root surfaces were subsequently treated with EDTA (PrefGel ${ }^{\circledR}$, Straumann, Basel, Switzerland) for $2 \mathrm{~min}$. After washing with saline sufficiently, three-layered autologous PDL-derived cell sheets were trimmed to the defect size and placed on the denuded root surface with a biodegradable polyglycolic acid mesh (Neoveil, $0.15 \mathrm{~mm}$ in thickness; Gunze, Tokyo), and the bony defect was filled with beta-tricalcium phosphate ( $\beta$ TCP) granules (Osferion $\AA$, G1, Olympus Terumo Biomaterials, Tokyo, Japan) (Fig. 2). Postoperative care included the systemic administration of azithromycin (Zithromac ${ }^{\circledR}$, Pfizer, Tokyo, Japan) $500 \mathrm{mg} /$ day for 3 days. Diclofenac sodium (Voltaren ${ }^{\circledR}$, Novartis Pharma, Tokyo, Japan) was provided as needed for analgesia. Postoperative supragingival professional tooth cleaning, and clinical and radiographic measurements were scheduled for 6-month post-surgery (Table 2).

\subsection{Study end points}

The primary endpoint was the safety of autologous PDL-derived cell sheets in patients with severe periodontitis. Safety was assessed based on clinical findings and the pain scoring, which were generated from interviews with a 4-degree verbal rating scale at $1,2,4,8,12$, and 24 weeks after the transplantation (Table 2).

The secondary endpoints evaluated the efficacy of this treatment. Clinical parameters, including gingival index (GI), plaque index (PI), probing pocket depth (PPD), bleeding on probing (BOP), and clinical attachment level (CAL), were recorded to evaluate the therapeutic effect at baseline, 3 months, and 6 months. Radiographic evaluation was performed with the cone beam X-ray computed tomography (CBCT) (3DX, J. Morita, Kyoto, Japan) and the manufacturer's software system (I-View; Morita) at baseline and 6 months. The deepest point of defect was selected in each case and linear bone height was measured by two blinded examiners. The average distance between cementoenamel junction (CEJ) and the deepest point of the defect was analyzed. Mid-long-term follow-up has been performed with patients' agreements, and CBCT has been taken at a minimum of 6 month-intervals.

\subsection{Statistical analysis}

The changes between baseline and observation periods, in terms of the primary and secondary endpoints, were statistically analyzed. Results are expressed as the mean \pm standard division (SD), and the Wilcoxon signed-rank test was carried out. A twosided probability $(\mathrm{P})<0.05$ was considered significant.

\section{Results}

In this clinical study, 10 cases ( 5 female) underwent periodontal surgery and received autologous PDL-derived cell sheet transplantations from November 2011 to May 2014. The median age of patients was 46 years old (range 33-63) at the first informed consent. Although the observation period of each patient was finished 6 months after the transplantation in the protocol of this clinical study, transplanted patients were followed up for an average of 55 months (range 15-79).

Tooth extraction for harvesting autologous PDL-derived cells was performed without significant morbidity. PDL-derived cells from a single tooth were expanded for 2 weeks and plated on 6 temperature responsive culture dishes at a cell density of $2-4 \times 10^{4}$ cells/dish. After 2 weeks of additional culture with osteoinductive supplements, tight and thick 3-layered PDL-derived cell sheets $\left(4.8 \pm 2.1 \times 10^{5}\right.$ cells $\left./ \mathrm{cm}^{2}\right)$ were created. The quality control tests were performed before the transplantation 

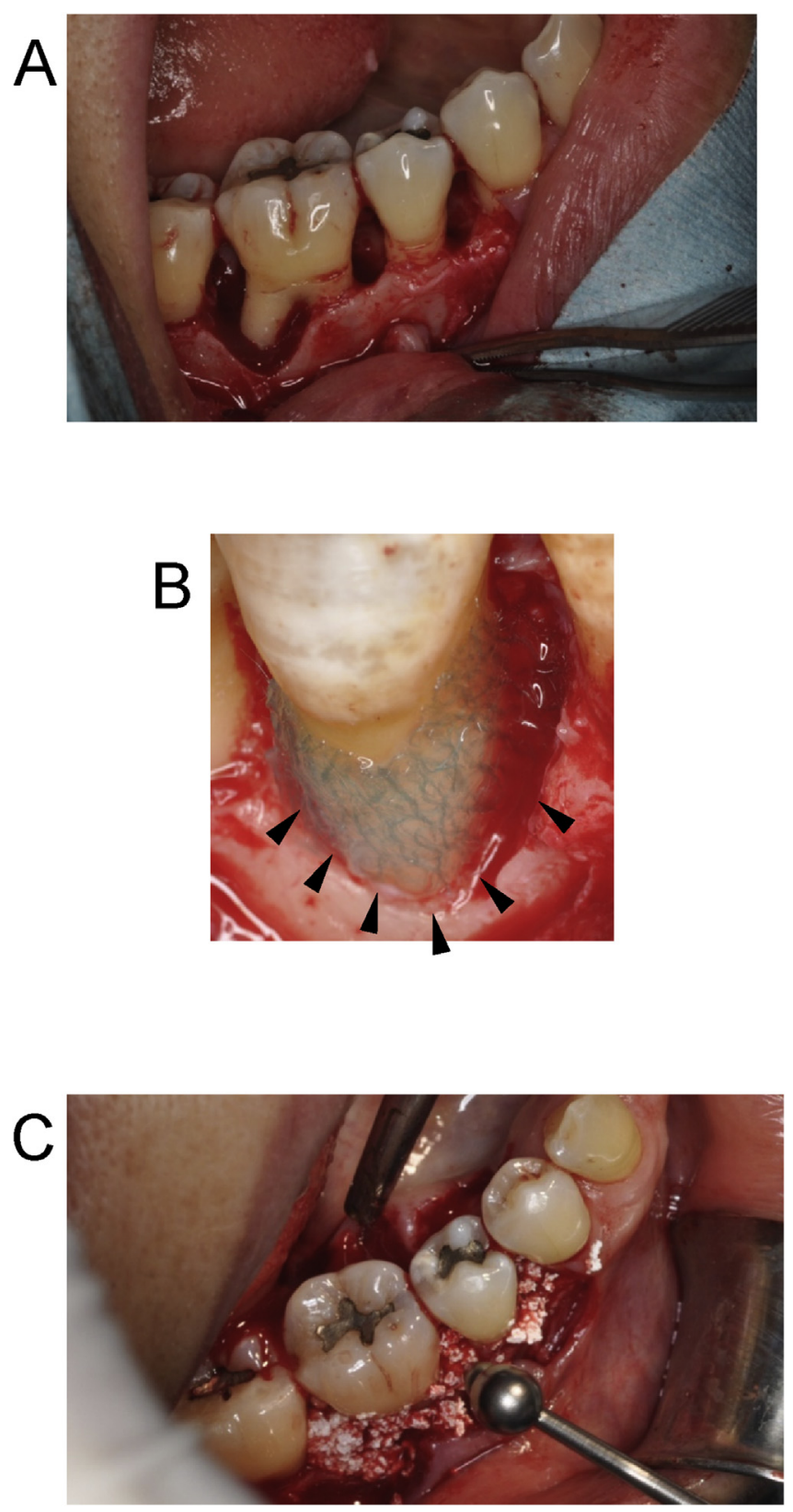

Fig. 2. Surgical Procedure. Following open flap surgery in accordance with the modified Widman procedure (Fig. 2A), a 3-layered PDL-derived cell sheet retained with woven PGA was trimmed to the defect size and set on the root surface (black triangle). Woven PGA was set outside of PDL-derived cell sheets (Fig. 2B). $\beta$-tricalcium phosphate granules were filled into the bony defect to cover the cell sheets (Fig. 2C).

(Supplemental Table 1), and all 10 products passed all tests established previously [16], demonstrating that all products possessed PDL-like characteristics. Multipotency of all products, other than \#6, were also shown after the induction of osteogenesis or adipogenesis (Supplemental Table 2), suggesting they also possessed multipotent mesenchymal stromal cell (MSC)-like properties [19]. For safety tests, the conditioned cell culture medium of intermediate products was outsourced to the inspection company (SRL Inc., Tokyo, Japan) to determine any contamination before shipping. The final products were also examined for microbial contamination, and they all passed the tests (Supplemental Table 3).

Surgical procedures were performed uneventfully. After the surgery, some patients complained of pain; however, the pain dissipated uneventfully, as expected for conventional periodontal surgeries [20] (Supplemental Table 4). Specifically, patient \#2 complained of severe pain during eating and cramping pain 1 week after the surgery. She previously received periodontal surgery twice, and she mentioned the pain after transplantation was similar to previous periodontal surgery. Other complications associated with PDL-derived cell sheet transplantation were not reported.

The changes in clinical and radiographic parameters are presented in Table 3. The clinical parameters, including CAL, PPD, and linear bone height, were significantly improved at 3 months and 6 months compared to those of baseline. The mean CAL gains were $2.5 \pm 1.8 \mathrm{~mm}$ at 3 months and $2.5 \pm 2.6 \mathrm{~mm}$ at 6 months. The mean PPD reductions were $2.8 \pm 1.3 \mathrm{~mm}$ at 3 month and $3.2 \pm 1.9 \mathrm{~mm}$. The CT-assisted imaging evaluation confirmed the gain of linear bone height was $2.3 \pm 1.8 \mathrm{~mm}$ at 6 months (Table 3 ) and there was no evidence of ankylosis in any of the transplanted sites by CBCT analysis. There was no significant change in GI and PI.

Representative cases are shown in Fig. 3. Fig. 3A, B, and C shows CBCT images of Patient \#1, \#4 and \#10, respectively. Specifically, dramatic healing was observed in Fig. 3B. The patient was a 63year-old woman with loss of alveolar bone over the root apex with furcation involvement in the lower right second molar as the result of periodontitis and occlusal trauma. After the initial periodontal therapy, deep periodontal defects in the lower right premolars and molars were treated with the tissue engineered cell sheets. Six months after the surgery, the patient recovered occlusal function, and periodontal regeneration was confirmed by CBCT (Fig. 3B, center). As of this writing, 35 months after surgery, the patient has reported no problems with the transplantation, and the bone level has been stable (Fig. 3B, right).

\section{Discussion}

A promising cell source for periodontal regeneration is stem cells derived from PDL tissues [21], and the mode of action of periodontal regeneration includes how PDL-derived stem cells are recruited, proliferate, and differentiate into periodontal components with an appropriate spatiotemporal sequence [22]. In order to achieve this regeneration, various tissue engineering approaches have been introduced [23]. Our laboratory has developed "Cell Sheet Engineering Technology" [24,25], and the safety and efficacy of PDL-derived cell sheets has been previously tested in canine models [12,13]. In addition, we have optimized culture conditions for human PDL-derived cells [6], verified the quality of human PDL-derived cells $[16,17]$, and received clinical study approval in January 2011 from the Minister for Health, Labour and Welfare in Japan.

For this clinical study, 12 patients were enrolled; however, 2 cases were dropped during cell cultivation. These cases were dropped because the cells did not proliferate well in one case, and a contamination of coagulase-negative staphylococci (CNS) occurred in the other case. In the former case, it is possible that the attached PDL tissue was too small because the cell source was residual roots with caries (upper right first molar). In the latter, it is possible that the initial washing of the tooth was insufficient, because larger blood clots than expected were attached to the extracted tooth. In contrast, the creation of PDL-derived cell sheets for the other 10 cases were successfully accomplished and passed all the safety and quality control tests. Therefore, the protocol for isolating and culturing human PDL-derived cells was optimized and verified in this study.

The quality of PDL-derived cells was tested in all cases. From the quality control testing results before shipping, their viability and response to osteoinductive medium was as expected for PDL- 
Table 2

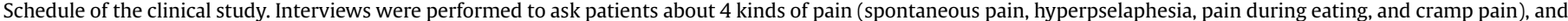

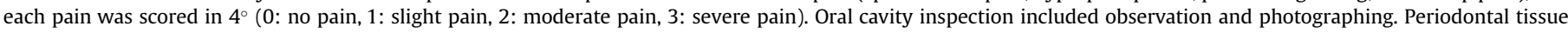

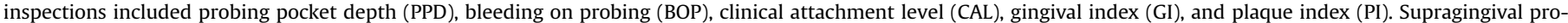
fessional tooth cleaning was performed as preventive treatment.

\begin{tabular}{|c|c|c|c|c|c|c|c|c|c|}
\hline \multirow[t]{3}{*}{ Item } & \multirow[t]{3}{*}{ Before registration } & \multirow[t]{3}{*}{ Before transplantation } & \multirow[t]{3}{*}{ Transplantation } & \multicolumn{6}{|c|}{ After transplantation } \\
\hline & & & & \multicolumn{2}{|c|}{ Week } & \multicolumn{4}{|c|}{ Month } \\
\hline & & & & 1 & 2 & 1 & 2 & 3 & 6 \\
\hline $\begin{array}{l}\text { Patient background } \\
\text { Patient agreement } \\
\text { Blood tests for infectious disease } \\
\text { Interview } \\
\text { Oral cavity inspection } \\
\text { Transplantation of cell sheet } \\
\text { CBCT } \\
\text { Periodontal tissue inspections } \\
\text { Responding to adverse events } \\
\text { Preventive treatment }\end{array}$ & $\begin{array}{l}\bullet \\
\bullet \\
\bullet\end{array}$ & • & $\begin{array}{l}0 \\
0 \\
0\end{array}$ & 0 & 0 & ○ & 0 & $\begin{array}{l}0 \\
0\end{array}$ & $\begin{array}{l}0 \\
0 \\
0\end{array}$ \\
\hline
\end{tabular}

Table 3

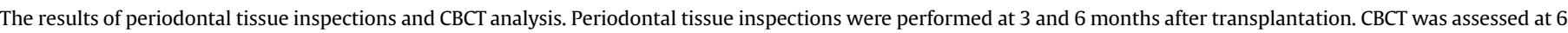
months after the transplantation.

\begin{tabular}{|c|c|c|c|c|c|}
\hline \multirow[t]{2}{*}{ Pt.\# } & \multicolumn{2}{|l|}{$3 \mathrm{M}$} & \multicolumn{3}{|l|}{$6 \mathrm{M}$} \\
\hline & Gain of CAL & Reduction of PPD & Gain of CAL & Reduction of PPD & Gain of linear bone \\
\hline 1 & 2 & 3 & 3 & 3 & 2.31 \\
\hline 2 & 1 & 1 & 3 & 2 & 0.50 \\
\hline 3 & 1 & 3 & 1 & 3 & 1.07 \\
\hline 4 & 5 & 5 & 7 & 7 & 5.89 \\
\hline 5 & 3 & 4 & 1 & 4 & 3.59 \\
\hline 6 & 3 & 2 & 2 & 2 & 1.42 \\
\hline 7 & 2 & 3 & 0 & 2 & 1.37 \\
\hline 8 & 1 & 2 & 1 & 2 & 0.74 \\
\hline 9 & 6 & 4 & 7 & 6 & 1.36 \\
\hline 10 & 1 & 1 & 0 & 1 & 4.60 \\
\hline Average & 2.5 & 2.8 & 2.5 & 3.2 & 2.29 \\
\hline SD & 1.8 & 1.3 & 2.6 & 1.9 & 1.81 \\
\hline
\end{tabular}

derived cells. Both the alkaline phosphatase (ALP) activity and ALP positive rate were higher than the predetermined criteria (Supplemental Table 1). In addition, the gene expression of periostin was sufficient in all cases, suggesting transplanted cells retained PDL-like phenotype $[6,26]$ without gingival fibroblastic phenotypes. We also performed CFU-F assays and multidifferentiation assays using the remaining cells with fetal bovine serum, and all but \#6 possessed MSC-like phenotypes (Supplemental Table 2). The difficulty in inducing calcified nodule formation from all sample may be due to the individual variation, although they all possessed colony forming activity and adipogenic potential in this study.

Autologous PDL-derived cell sheets combined with $\beta$-TCP bone fillers improved clinical and radiographic outcomes in this clinical study. So far, there have been no serious complications attributed to the transplanted cells in the mid-long-term follow-up (mean $55 \pm 19$ months). Two cases are followed by a local clinic after the 15 and 35 month follow-ups due to long distance.

The $\beta$-TCP used in this study was small size biodegradable granules and was shown to be replaced by newly-formed bone by 6 months [27]. In this study, histological data could not be collected, because of ethical restrictions; however, particles of implanted $\beta$-TCP were not observed, and bone-like opaque mass appeared in all cases 6 months after the surgery. Most of the $\beta$ TCP seemed biodegraded as the manufacturer predicted, therefore, the changes of linear bone height could be determined in this protocol. Furthermore, the bone level was stable, and the bone trabecula-like structures were elucidated in this study (Fig. 3). A previous clinical trial showed that the gain of linear bone by $\beta$-TCP alone was $0.9 \pm 0.1 \mathrm{~mm}$ after 6 months [28]. It is well-known that the defect morphology is one of the influencing factors of periodontal regeneration [29]. Our study included larger and more complex cases, and we were able to observe improvement of many parameters in this clinical study. Therefore, PDL-derived cell sheets are a widely applicable therapy for treating severe periodontal defects. During mid-long-term follow-up of this study, a randomized clinical trial of autologous PDL stem cells with bovine-derived bone mineral materials for periodontal regeneration was reported [30], based on the preliminary case reports [31]. The authors could not find significant therapeutic efficacy of PDL stem cells; however, it may be due to the slow bioresorbability of bovine materials or one of the chosen inclusion criteria, where small size defects were selected. Further investigation is needed to select appropriate materials and defect shapes for cytotherapeutic approach of periodontal regeneration.

In this study, CBCT was utilized for evaluation of periodontal bony regeneration. The accuracy of $\mathrm{CBCT}$ has been demonstrated [32], and it is also reported that CBCT is useful for measuring periodontal defects [33]. In addition, only interproximal defects can be evaluated with intraoral radiographs, thus, we introduced CBCT for radiographic assessment of periodontal regeneration, and the linear bone distance between the cemento-enamel junction and the base of the defect was measured by two blinded examiners. 


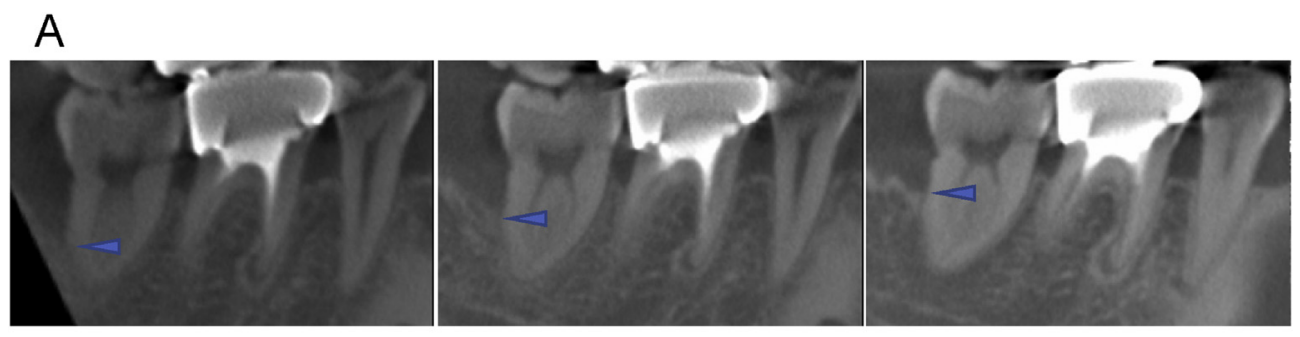

B
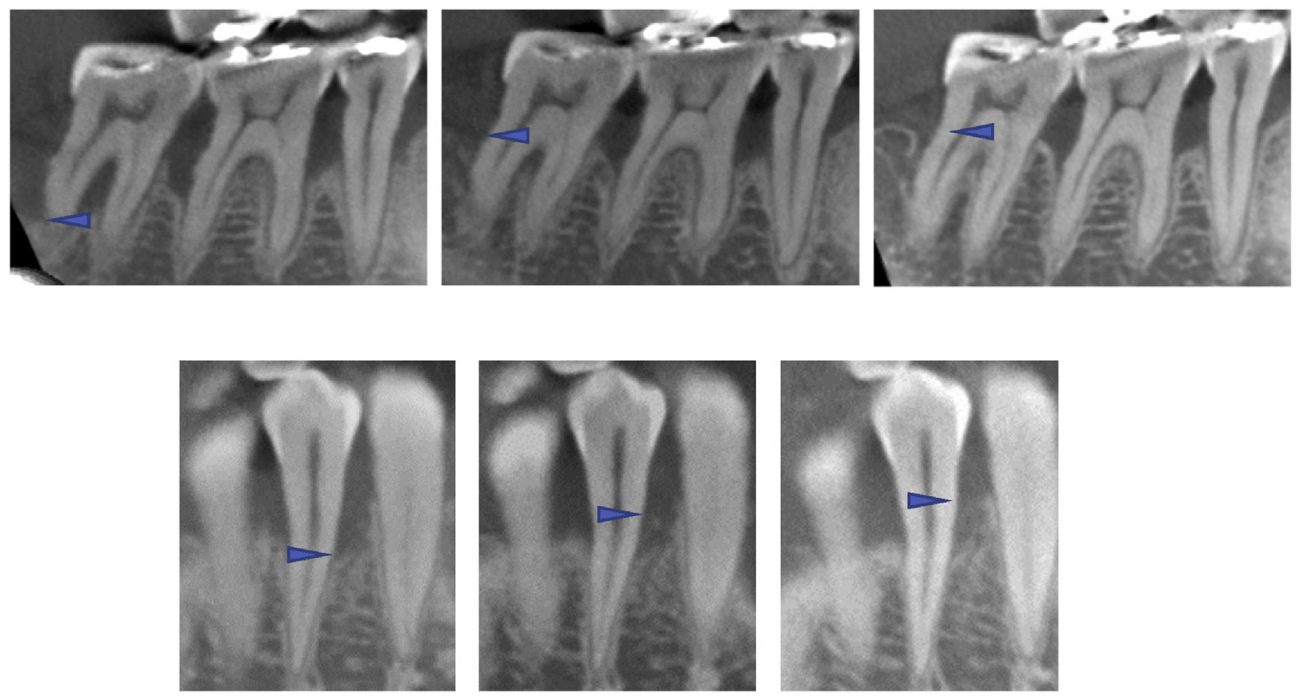

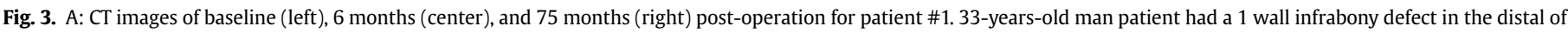

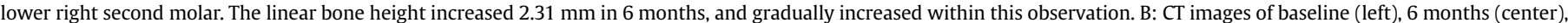

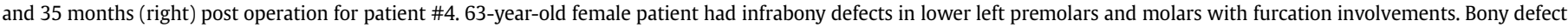

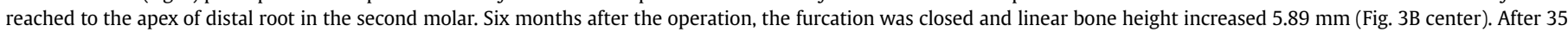

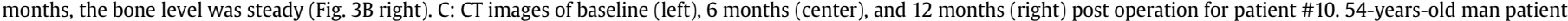

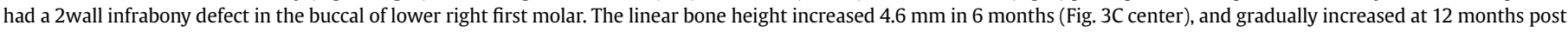
operation (Fig. $3 \mathrm{C}$ right). Arrowheads indicates the most apical portion of bone defects.

The main limitation of this autologous transplantation study was the small number of patients who had a redundant tooth with healthy periodontal tissue for use as a cell source. This problem can be overcome with the use of allogeneic MSCs, because MSCs possess immunomodulatory activities, which should minimize immune rejection [34]. In the dental field, young teeth are routinely extracted for orthodontic reasons or impaction, then discarded as medical waste in clinics, thus allogeneic dental tissues-derived cells can be routinely obtained. As patients in non-transplantation groups cannot receive the transplantation despite tooth extraction, it is ethically difficult to commence a randomized study with autologous cells. Additionally, autologous cells cannot be used for transplantation to any patients other than the original donor, resulting in expensive medical costs. Therefore, we are now planning to establish an allogeneic cell bank of PDL derived MSCs, and optimal procedures for selection, cryopreservation, and stocking of stem cells that have been accumulating for future allogeneic clinical trial.

\section{Conflict of interest}

T.O. is a founder and director of the board of CellSeed, Inc., and holds technology licensing and patents from Tokyo Women's Medical University. T.O. also is a stakeholder of CellSeed, Inc. Tokyo Women's Medical University receives research funds from CellSeed, Inc. No other potential conflicts of interest relevant to this article were reported.

\section{Acknowledgments}

The authors thank Hozue Kuroda of the Institute of Advanced Biomedical Engineering and Science, Tokyo Women's Medical University, for excellent cell culturing in the cell processing center and technical support; Yoshiaki Hara of Belledame dental clinic, for recruiting a patient; and Hallie Thorp and Sebastian Sjöqvist, of the Institute of Advanced Biomedical Engineering and Science, Tokyo Women's Medical University, for English editing and valuable advice.

This study was supported by the Creation of Innovation Centers for Advanced Interdisciplinary Research Areas Program of the Project for Developing Innovation Systems "Cell Sheet Tissue Engineering Center (CSTEC)" from the Ministry of Education, Culture, Sports, Science and Technology (MEXT), Japan.

\section{Appendix A. Supplementary data}

Supplementary data related to this article can be found at https://doi.org/10.1016/j.reth.2018.07.002.

\section{References}

[1] Pihlstrom BL, Michalowicz BS, Johnson NW. Periodontal diseases. Lancet 2005;366:1809-20.

[2] Hegedus $Z$. The rebuilding of the alveolar processes by bone transplantation. Dental Cosmos 1923;65:736-42. 
[3] Jayakumar A, Rohini S, Naveen A, Haritha A, Reddy K. Horizontal alveolar bone loss: a periodontal orphan. J Indian Soc Periodontol 2010;14:181-5.

[4] Iwata T, Washio K, Yoshida T, Ishikawa I, Ando T, Yamato M, et al. Cell sheet engineering and its application for periodontal regeneration. J Tissue Eng Regen Med 2015;9:343-56.

[5] Seo BM, Miura M, Gronthos S, Bartold PM, Batouli S, Brahim J, et al. Investigation of multipotent postnatal stem cells from human periodontal ligament. Lancet 2004;364:149-55.

[6] Iwata T, Yamato M, Zhang Z, Mukobata S, Washio K, Ando T, et al. Validation of human periodontal ligament-derived cells as a reliable source for cytotherapeutic use. J Clin Periodontol 2010;37:1088-99.

[7] Yamada N, Okano T, Sakai H, Karikusa F, Sawasaki Y, Sakurai Y. Thermoresponsive polymeric surfaces; control of attachment and detachment of cultured cells. Makromol Chem Rapid Commun 1990;11:571-6.

[8] Nishida K, Yamato M, Hayashida Y, Watanabe K, Maeda N, Watanabe H, et al. Functional bioengineered corneal epithelial sheet grafts from corneal stem cells expanded ex vivo on a temperature-responsive cell culture surface. Transplantation 2004;77:379-85.

[9] Miyagawa S, Domae K, Yoshikawa Y, Fukushima S, Nakamura T, Saito A, et al. Phase I clinical trial of autologous stem cell-sheet transplantation therapy for treating cardiomyopathy. J Am Heart Assoc 2017;6.

[10] Ohki T, Yamato M, Ota M, Takagi R, Murakami D, Kondo M, et al. Prevention of esophageal stricture after endoscopic submucosal dissection using tissueengineered cell sheets. Gastroenterology 2012;143. 582-8 e1-2.

[11] Yamamoto K, Yamato M, Morino T, Sugiyama H, Takagi R, Yaguchi Y, et al. Middle ear mucosal regeneration by tissue-engineered cell sheet transplantation. NPJ Regen Med 2017:2:6.

[12] Iwata T, Yamato M, Tsuchioka H, Takagi R, Mukobata S, Washio K, et al. Periodontal regeneration with multi-layered periodontal ligament-derived cell sheets in a canine model. Biomaterials 2009;30:2716-23.

[13] Tsumanuma Y, Iwata T, Washio K, Yoshida T, Yamada A, Takagi R, et al. Comparison of different tissue-derived stem cell sheets for periodontal regeneration in a canine 1-wall defect model. Biomaterials 2011;32:5819-25.

[14] Iwata T, Yamato M, Ishikawa I, Ando T, Okano T. Tissue engineering in periodontal tissue. Anat Rec 2014;297:16-25.

[15] Tsumanuma Y, Iwata T, Kinoshita A, Washio K, Yoshida T, Yamada A, et al. Allogeneic transplantation of periodontal ligament-derived multipotent mesenchymal stromal cell sheets in canine critical-size supra-alveolar periodontal defect model. Biores Open Access 2016;5:22-36.

[16] Washio K, Iwata T, Mizutani M, Ando T, Yamato M, Okano T, et al. Assessment of cell sheets derived from human periodontal ligament cells: a pre-clinical study. Cell Tissue Res 2010;341:397-404.

[17] Yoshida T, Washio K, Iwata T, Okano T, Ishikawa I. Current status and future development of cell transplantation therapy for periodontal tissue regeneration. Int J Dent 2012;2012:307024.

[18] Washio K, Kuroda H, Iwata T, Yoshida T, Yamato M, Okano T. Improved enzymatic treatment for accurate cell counting from extracellular matrix-rich periodontal ligament cell sheets. Int J Oral Maxillofac Implants 2014;29: e117-21.

[19] Dominici M, Le Blanc K, Mueller I, Slaper-Cortenbach I, Marini F, Krause D, et al. Minimal criteria for defining multipotent mesenchymal stromal cells. The International Society for Cellular Therapy position statement. Cytotherapy 2006;8:315-7.

[20] Curtis Jr JW, McLain JB, Hutchinson RA. The incidence and severity of complications and pain following periodontal surgery. J Periodontol 1985;56: 597-601.

[21] Bartold PM, Shi S, Gronthos S. Stem cells and periodontal regeneration. Periodontol 2000;2006(40):164-72.

[22] Miron RJ, Zhang YF. Osteoinduction: a review of old concepts with new standards. J Dent Res 2012;91:736-44.

[23] Chen FM, Sun HH, Lu H, Yu Q. Stem cell-delivery therapeutics for periodontal tissue regeneration. Biomaterials 2012;33:6320-44.

[24] Hasegawa M, Yamato M, Kikuchi A, Okano T, Ishikawa I. Human periodonta ligament cell sheets can regenerate periodontal ligament tissue in an athymic rat model. Tissue Eng 2005;11:469-78.

[25] Akizuki T, Oda S, Komaki M, Tsuchioka H, Kawakatsu N, Kikuchi A, et al. Application of periodontal ligament cell sheet for periodontal regeneration: a pilot study in beagle dogs. J Periodontal Res 2005;40:245-51.

[26] Somerman MJ, Archer SY, Imm GR, Foster RA. A comparative study of human periodontal ligament cells and gingival fibroblasts in vitro. J Dent Res 1988;67:66-70.

[27] Katagiri W, Osugi M, Kawai T, Hibi H. First-in-human study and clinical case reports of the alveolar bone regeneration with the secretome from human mesenchymal stem cells. Head Face Med 2016;12:5.

[28] Nevins M, Giannobile WV, McGuire MK, Kao RT, Mellonig JT, Hinrichs JE, et al Platelet-derived growth factor stimulates bone fill and rate of attachment level gain: results of a large multicenter randomized controlled trial J Periodontol 2005;76:2205-15.

[29] Reynolds MA, Kao RT, Camargo PM, Caton JG, Clem DS, Fiorellini JP, et al Periodontal regeneration - intrabony defects: a consensus report from the AAP Regeneration Workshop. J Periodontol 2015;86:S105-7.

[30] Chen FM, Gao LN, Tian BM, Zhang XY, Zhang YJ, Dong GY, et al. Treatment of periodontal intrabony defects using autologous periodontal ligament stem cells: a randomized clinical trial. Stem Cell Res Ther 2016;7:33.

[31] Feng F, Akiyama K, Liu Y, Yamaza T, Wang TM, Chen JH, et al. Utility of PDL progenitors for in vivo tissue regeneration: a report of 3 cases. Oral Dis 2010;16:20-8.

[32] Lascala CA, Panella J, Marques MM. Analysis of the accuracy of linear measurements obtained by cone beam computed tomography (CBCT-NewTom). Dentomaxillofac Radiol 2004;33:291-4.

[33] Misch KA, Yi ES, Sarment DP. Accuracy of cone beam computed tomography for periodontal defect measurements. J Periodontol 2006;77:1261-6.

[34] Caplan AI, Correa D. The MSC: an injury drugstore. Cell Stem Cell 2011;9: $11-5$ 